\title{
Crescimento Relativo e Composição do Ganho de Tecidos da Carcaça de Zebuínos de Quatro Raças ${ }^{1}$
}

\author{
André Mendes Jorge ${ }^{2}$, Carlos Augusto de Alencar Fontes ${ }^{3}$, Rafael da Costa Cervieri ${ }^{4}$
}

\begin{abstract}
RESUMO - Utilizaram-se 64 machos não-castrados das raças Gir, Guzerá, Mocho de Tabapuã e Nelore. Em cada raça, os animais foram divididos, aleatoriamente, em cinco categorias. Uma categoria foi abatida imediatamente, três receberam, em baias individuais, ração contendo 50\% de concentrado na MS ad libitum (I, II e III) e uma recebeu a mesma ração, em quantidade restrita, suprindo níveis de proteína e energia $15 \%$ acima da mantença. Os animais I, II e III foram abatidos ao atingirem pesos vivos individuais de 405,450 e $500 \mathrm{~kg}$, respectivamente. Adotou-se a equação de regressão do logaritmo da quantidade corporal de carcaça e de seus tecidos (muscular, adiposo e ósseo), em função do logaritmo do peso de corpo vazio. Na carcaça, o tecido adiposo, ósseo e muscular tiveram maior impulso para crescimento em idade mais tardia, precoce e intermediário, respectivamente. A carcaça apresentou alometria positiva, refletindo o seu desenvolvimento proporcionalmente maior que o do peso corporal vazio.
\end{abstract}

Palavras-chave: alometria, músculos, osso, tecido adiposo

\section{Relative Growth and Gain Composition of Carcass Tissues from Four Zebu Breeds}

\begin{abstract}
Sixty four uncastrated males from zebu breeds Gyr, Guzerat, Mocho de Tabapuã and Nellore were used. The animals from each breed were divided into five groups (categories). One group was ramdomly assigned to immediate slaughter, three groups were full-fed a ration containing 50\% concentrate, dry matter basis until reaching the slaughter weights of 405,450 and $500 \mathrm{~kg}$, respectively (group I, II and III). The fifth group was fed a restricted amount of the same ration to supply levels of protein and energy $15 \%$ above maintenance. Regression equations of log content of carcass and their tissues (muscle, adipose tissue and bone), as a function of log emptybody-weight, were fitted. Adipose, bone and muscular tissue presented higher growth in late, early and intermediary age, respectively. Carcass presented positive allometry reflecting greater proporcional development in relation to empty-body-weight.
\end{abstract}

Key Words: allometry, muscle, bone, adipose tissue

\section{Introdução}

Assim como para os órgãos, equações alométricas são utilizadas para expressar o crescimento dos tecidos muscular, adiposo e ósseo da carcaça em relação ao peso corporal e ao peso da carcaça.

Segundo Trenkle (1983), o tecido ósseo apresenta coeficiente de crescimento baixo $(b<1)$, sendo de maturidade precoce; o muscular, intermediário $(b=1)$ e o tecido adiposo alto $(b>1)$, sendo de maturidade tardia.

Osório et al. (1994), quando abateram bovinos holandeses, com pesos vivos (PV) de 375 a $550 \mathrm{~kg}$ e pesos de carcaça fria (PCARF) de 200 a $262 \mathrm{~kg}$, observaram crescimento ósseo em ritmo mais lento, do tecido adiposo mais rápido e dos músculos em ritmo igual ao do PV e PCARF. Os mesmos autores verificaram diminuição da proporção de ossos, aumento na proporção da gordura da carcaça e manutenção da proporção dos músculos com aumento do PV e PCARF.

Robelin et al. (1974) concluíram que a magnitude dos coeficientes de crescimento relativo dos tecidos da carcaça, de bovinos Friesian franceses, abatidos entre 9 a 15 meses de idade, foi comparável à já relatada para outros tipos de bovinos e para outras espécies, que estabelece para os ossos $(b=0,76)$, músculos $(\mathrm{b}=0,92)$ e gordura total da carcaça $(\mathrm{b}=1,58)$.

Estudando o efeito do peso vivo sobre o peso de carcaça (PCAR), Nour et al. (1983) concluíram que o peso de abate, como uma proporção do peso adulto, pode afetar a relação $\mathrm{PCAR} / \mathrm{PV}$, uma vez que, por

\footnotetext{
1 Projeto realizado na UFV em colaboração com a EPAMIG - Governador Valadares.

2 Professor Assistente Doutor do D.P.E.A./FMVZ/UNESP - Caixa Postal 560 - Botucatu - SP. CEP: 18618-000.

Pesquisador do CNPq. E.mail: jorgeam@fca.unesp.br

3 Professor Titular da UENF-CCTA/LZNA, CEP: 28015-620 - Campos - RJ. E.mail: cafontes@uenf.br

4 Mestre em Zootecnia. Doutorando em Zootecnia pela UNESP-FMVZ-Botucatu. E.mail: cervieri@bigfoot.com
} 
cada quilograma a mais no peso vivo, houve aumento de $0,74 \mathrm{~kg}$ no peso de carcaça, e afirmam que a equação obtida pode ser usada para estimar alterações no peso das carcaças, a partir do peso vivo.

Osório et al. (1983), analisando dados de 39.672 novilhos abatidos em frigorífico, de diferentes idades e pertencentes a várias raças, mostraram que o peso vivo foi responsável por $81 \%$ da variação total no peso da carcaça fria, com um coeficiente de regressão de 0,52. Os autores salientam que, como a relação entre peso de carcaça quente (PCARQ) e fria (PCARF) é alta, é de se esperar, igualmente, que o peso vivo estime com precisão o de carcaça quente.

Corroborando as informações anteriores, resultados de pesquisa mostram elevada relação entre o peso vivo e o peso de carcaça e, por ser de fácil obtenção, o peso vivo é um bom preditor do peso de carcaça (PCAR) (Zanotta et al., 1980; Guerreiro et al., 1986; Jardim et al., 1987).

Recentemente, Jardim et al. (1996), trabalhando com novilhos Hereford abatidos aos 36 meses, obteve a equação de regressão: PCARQ $=3,97+0,47 * \mathrm{PV}$, com um coeficiente de determinação de $90,46 \%$. Da mesma forma, Castillo Estrada (1996), abatendo animais Nelore, $F_{1}$ Nelore-Angus, $F_{1}$ Nelore-Holandês e $\mathrm{F}_{1}$ Nelore-Normando, em diferentes estádgios de maturidade fisiológica, obteve as seguintes equações e respectivos coeficientes de determinação: PCARQ $=-48,93+0,67 * \mathrm{PV}, \mathrm{r}^{2}=0,96$; $\mathrm{PCARF}=-51,56+0,67 * \mathrm{PV} \quad \mathrm{r}^{2}=0,96$.

O peso do conteúdo do trato gastrintestinal (TGI) exerce influência direta sobre o ganho de peso vivo (Berg \& Butterfield, 1976; Fox et al., 1976; Fontes, 1995). Desse modo, quando se deseja expressar mais adequadamente o desempenho animal nos experimentos de alimentação e sistemas de produção, pode-se utilizar o peso corporal vazio (PCVZ). Porém, além do custo e mão-de-obra, o PCVZ só pode ser determinado, após o abate, deduzindo-se do PV o peso do conteúdo do TGI ou somando-se os pesos de todos os componentes do corpo do animal, tornando-se inviável nos casos de avaliações seguidas em um mesmo animal.

Uma alternativa mais prática seria estimar o PCVZ a partir do PV. Com este objetivo, muitas pesquisas foram conduzidas e permitiram concluir que, a partir do PV, pode-se estimar o PCVZ com bastante precisão (ARC, 1980; Wright \& Russel, 1984) por intermédio da equação: $\mathrm{PCVZ}=-43,1+$ $0,93 * \mathrm{PV}$, com r $^{2}=0,98$.

R. Bras. Zootec., v.32, n.4, p.986-991, 2003
Fontes (1995), em uma análise conjunta de dados obtidos em diferentes experimentos, referentes a 281 animais das raças zebuínas, mestiços de raças européias leiteiras e zebuínas e mestiços de raças européias de corte e zebuínas, com pesos variando entre 200 e $550 \mathrm{~kg}$, obteve as seguintes equações de predição: $\mathrm{PCVZ}=-19,61+0,92 * \mathrm{PV}, \mathrm{r}^{2}=0,97$, para zebuínos e $\mathrm{PCVZ}=-34,34+0,92 * \mathrm{PV}, \mathrm{r}^{2}=0,97$ para mestiços europeu-zebu.

Castillo Estrada (1996), ao abater animais Nelore, $F_{1}$ Nelore-Angus, $F_{1}$ Nelore-Holandês e $F_{1}$ NeloreNormando, com pesos vivos entre 350 e $550 \mathrm{~kg}$, obteve a equação: $\mathrm{PCVZ}=-50,68+0,97 * \mathrm{PV}$, com um coeficiente de determinação de $97,0 \%$.

O presente estudofoi conduzido com o objetivo de avaliar o crescimento e as mudanças da composição da carcaça e de seus tecidos em bovinos das raças Gir, Guzerá, Nelore e Mocho Tabapuã, abatidos em diferentes estádios de maturidade.

\section{Material e Métodos}

Utilizaram-se 64 bovinos machos não-castrados, confinados em baias individuais, sendo 16 Gir, 16 Guzerá, 15 Nelore e 16 Mocho Tabapuã, com idade média de 24 meses e pesos vivos (PV) médios iniciais de $357,6 \pm 32,95 ; 362,0 \pm 28,95 ; 376,4 \pm 28,56$ e 368,6 $\pm 25,83 \mathrm{~kg}$, respectivamente. Estes animais foram confinados em baias individuais concretadas com área de $30 \mathrm{~m}^{2}$, dispondo de comedouro e bebedouro de cimento.

Os animais de cada raça foram distribuídos em cinco categorias: abate inicial (AB); alimentação restrita (AR); alimentação ad libitum até o abate, a um peso vivo de 405, 450 e $500 \mathrm{~kg}$ (categorias I, II e III), respectivamente. Após período de adaptação, foram abatidos os animais do grupo $\mathrm{AB}$, servindo como referência no estudo da composição corporal inicial dos animais.

Os animais dos grupos I, II e III receberam, durante o período experimental, uma ração balanceada ad libitum, formulada segundo as normas do NRC (1984) de modo a permitir um ganho diário de $1,1 \mathrm{~kg}$, atendendo, ao mesmo tempo, às exigências de proteína degradável no rúmen (PDR) e proteína não-degradável no rúmen (PNDR), segundo o ARC (1980). Procurouse sempre manter a proporção concentrado: volumoso (feno de capim-braquiária) próxima de 1:1, na matéria seca (MS). A ração foi fornecida aos animais da categoria alimentação restrita (AR) em quantidades 
limitadas, de forma a ingerirem quantidades de energia e proteína $15 \%$ acima das exigências de mantença. $\mathrm{O}$ concentrado constituiu-se de $76,5 \%$ de milho em grão triturado, $20,1 \%$ de farelo de soja, $1,6 \%$ de uréia e $1,8 \%$ de mistura mineral. A ração apresentou $83,8 \%$ de MS, $12,7 \%$ de proteína bruta e 2,42 Mcal $/ \mathrm{kg}$ de energia metabolizável, na base da MS.

O período experimental não teve duração préfixada, uma vez que os animais eram abatidos assim que atingiam os pesos vivos (PV) preestabelecidos de 405,450 ou $500 \mathrm{~kg}$, correspondentes as tratamentos (categorias) I, II e III, respectivamente.

Para cada raça, na medida em que um animal da categoria II atingia o peso de abate, o animal do grupo de alimentação restrita (AR) mais semelhante a ele quanto ao peso e à condição corporal, no início do experimento, era também abatido.

Antes do abate, os animais eram submetidos a um período de jejum de 16 horas, com livre acesso à água. Após o abate, a carcaça era dividida em duas metades, pesadas individualmente e levadas à câmara fria, por aproximadamente 18 horas, a $-5^{\circ} \mathrm{C}$. Decorrido este tempo, na metade esquerda da carcaça, retirava-se a secção tranversal, da qual se destacava a secção segundo Hankins \& Howe (1946), determinando-se as proporções dos componentes físicos (músculo, tecido adiposo e ossos). As proporções de músculo, tecido adiposo e ossos da carcaça foram determinadas com base nas proporções desses componentes na secção $\mathrm{HH}$, por meio das equações a seguir desenvolvidas por Hankins \& Howe (1946): Músculo $=16,08+0,80 * X$; Tecido Adiposo $=3,54+$ $0,80 * \mathrm{X}$ e Ossos $=5,52+0,57 * \mathrm{X}$, em que $\mathrm{X}$ é a porcentagem do componente na secção $H H$.

O peso corporal vazio (PCVZ) dos animais-referência $(\mathrm{AB})$ foi determinado somando-se peso da carcaça, sangue, cabeça, pés, couro, cauda, vísceras e órgãos. Relações específicas entre o PCVZ e o PV foram determinadas para animais de cada raça. $O$ valor obtido para cada raça foi utilizado para se estimar o PCVZ inicial dos animais experimentais das categorias remanescentes (Alimentação Restrita, I, II e III). O PCVZ final destes animais foi determinado de modo semelhante ao obtido pelos animais-referência (AB), por ocasião do abate. A relação observada para os animais-referência $(\mathrm{AB})$, entre peso de carcaça e o PCVZ, foi utilizada para estimar o peso inicial de carcaça dos animais remanescentes.

As análises estatísticas foram feitas utilizando-se o
programaLSMLMW, versão PC-1, segundoHarvey(1987).

No estudo do crescimento relativo da carcaça e seus tecidos (músculo, tecido adiposo e ossos), adotouse a equação de regressão do logaritmo da quantidade corporal de carcaça e seus tecidos (músculo, tecido adiposo e ossos), em função do logaritmo do peso do corpo vazio (PCVZ), conforme o modelo abaixo:

$$
Y_{i j}=m+b_{i} X_{i j}+e_{i j}
$$

em que: $Y_{i j}=$ logaritmo da quantidade total de carcaça e seus tecidos (músculo, tecido adiposo e ossos) $(\mathrm{kg})$ no corpo vazio, do animal $\mathrm{j}$ da raça $\mathrm{i} ; \mathrm{m}=$ efeito da média (intercepto); $b_{i}=$ coeficiente de regressão do logaritmo da quantidade de carcaça e seus tecidos (músculo, tecido adiposo e ossos) $(\mathrm{kg})$ em função do logaritmo do peso do corpo vazio, para a raça i, em que i =1, Gir; 2, Guzerá; 3, Nelore; 4, Mocho Tabapuã; $\mathrm{X}_{\mathrm{ij}}=\log$ aritmo do peso do corpo vazio, do animal $\mathrm{j} \mathrm{da}$ raça $i$; $e_{i j}=$ erro aleatório, pressuposto normalmente distribuído, com média zero e variância $\sigma^{2}$.

Aplicou-se o teste de identidade de modelos (Graybill, 1976), para se pesquisar a existência de diferenças entre as equações referentes a várias raças.

Equações de predição da quantidade de carcaça e seus tecidos (músculo, tecido adiposo e ossos) (kg), por $\mathrm{kg}$ de ganho de peso corporal vazio (GPCVZ), foram obtidas, por derivação das equações de regressão acima, obtendo-se as equações do tipo $\mathrm{Y}^{\prime}=\mathrm{b}^{*} 10^{\mathrm{a} *} \mathrm{X}^{\mathrm{b}-1}$, em que: $\mathrm{Y}^{\prime}=$ quantidade de carcaça e seus tecidos (músculo, tecido adiposo e ossos) (kg) porkg de GPCVZ; a e $b=$ intercepto e coeficiente de regressão, respectivamente, das equações de regressão da quantidade de carcaça e seus tecidos (músculo, tecido adiposo e ossos) $(\mathrm{kg})$ no corpo vazio; $\mathrm{X}=\mathrm{PCVZ}$ em $(\mathrm{kg})$.

De modo semelhante, foram ajustadas equações de predição do peso de carcaça quente (PCARQ), peso de carcaça fria (PCARF) e peso corporal vazio (PCVZ) em função do peso vivo (PV) em jejum.

Nas equações de predição do PCQ, PCARF e PCVZ, em função do PV, adotou-se o modelo abaixo:

$$
\mathrm{Y}_{\mathrm{ij}}=\mathrm{m}+\mathrm{b}_{1 \mathrm{i}} \mathrm{X}_{\mathrm{ij}}+\mathrm{e}_{\mathrm{ij}}
$$

em que: $Y_{i j}=$ pesos de carcaça quente, carcaça fria e de corpo vazio, do animal $\mathrm{j}$, da raça $\mathrm{i} ; \mathrm{m}=$ efeito da média (intercepto); $b_{1 \mathrm{i}}=$ coeficiente de regressão linear dos pesos de carcaça quente, de carcaça fria e de corpo vazio, em função do peso vivo, para a raça $i$, em que i = 1, Gir; 2, Guzerá; 3, Nelore; 4, Mocho Tabapuã; $X_{i j}=$ peso vivo do animal $j$, da raça $i$; $\mathrm{e}_{\mathrm{ij}}=$ erro aleatório, pressuposto normalmente distribuído, com média zero e variância $\sigma^{2}$. 


\section{Resultados e Discussão}

O teste de identidade de modelos (Graybill, 1976), aplicado às equações de regressão do logaritmo do peso de músculos, tecidos adiposo, ossos da carcaça e peso da carcaça $(\mathrm{kg})$, em função do logaritmo do PCVZ, para as quatro raças estudadas (Gir, Guzerá, Nelore e Mocho Tabapuã), indicou não haver $(\mathrm{P}>0,05)$ diferença entre as raças. Desse modo, para se estimarem os pesos de músculos, tecido adiposo, ossos da carcaça e peso da carcaça (Tabela 1), no PCVZ, adotou-se equação geral comum às quatro raças.

Os coeficientes de determinação $\left(\mathrm{r}^{2}\right)$ das equações de regressão, para músculos, tecido adiposo e carcaça, variaram entre 0,81 e 0,98 , mostrando bom ajustamento das equações aos dados experimentais. O ajustamento da equação aos dados para ossos não alcançaram nível semelhante ao de músculos, tecido adiposo e da carcaça, provavelmente, devido à pequena variação na proporção de ossos, em relação ao peso corporal vazio, pelo fato de os animais se encontrarem em fase final de crescimento.

Os coeficientes de regressão (b) das equações da Tabela 1 revelam a intensidade de desenvolvimento das partes em relação ao PCVZ. O tecido adiposo cresceu em taxa mais elevada que o PCVZ como um

Tabela 1 - Parâmetros das equações de regressão do logarítmo do peso de músculos, tecido adiposo, ossos da carcaça e do peso de carcaça $(\mathrm{kg})$ em função do logarítmo do peso corporal vazio (PCVZ), para quatro raças zebuínas (Gir, Guzerá, Nelore e Mocho Tabapuã)

Table 1 - Parameters of logarithm regression equations of muscles, adipose tissue and bone carcass and carcass weight $(\mathrm{kg})$ on the empty body weight $(\mathrm{kg})$ logarithm from four zebu breeds (Gyr, Guzerat, Nellore and Mocho Tabapuã

\begin{tabular}{|c|c|c|}
\hline $\begin{array}{l}\text { Componente } \\
\text { Component }\end{array}$ & \multicolumn{2}{|c|}{$\begin{array}{l}\text { Parâmetros das equações de regressão } \\
\text { Parameters of regression equations }\end{array}$} \\
\hline Intercepto & Coeficiente $\beta$ & $\mathrm{r}^{2}$ \\
\hline $\begin{array}{l}\text { Músculos } \\
\text { Muscle }\end{array}$ & $-0,191550$ & $0,8967150,81^{* *}$ \\
\hline $\begin{array}{l}\text { Tecido adiposo } \\
\text { Adipose tissue }\end{array}$ & $-3,005809$ & $1,8666480,81^{* *}$ \\
\hline $\begin{array}{l}\text { Ossos } \\
\text { Bone }\end{array}$ & 0,007594 & $0,6078890,51^{* *}$ \\
\hline $\begin{array}{l}\text { Carcaça } \\
\text { Carcass }\end{array}$ & $-0,485557$ & $1,1082220,98^{* *}$ \\
\hline
\end{tabular}

Significativo $(\mathrm{P}<0,01)$.

Significant $(P<.01)$.

R. Bras. Zootec., v.32, n.4, p.986-991, 2003 todo, enquanto o tecido ósseo teve crescimento mais lento e o tecido muscular, crescimento intermediário. Esse resultado é sustentado por Berg \& Butterfield (1976), os quais afirmam que o tecido ósseo tem seu desenvolvimento máximo em fase mais precoce da vida do animal. A carcaça apresentou alometria positiva $(b>1)$, refletindo o seu desenvolvimento proporcionalmente maior que o do PCVZ, especialmente em função da deposição de gordura. Estes resultados estão de acordo com Robelin et al. (1974), Black (1989) e Osório et al. (1994), refletindo as diferenças de precocidade do desenvolvimento dos diferentes tecidos da carcaça, conforme descrito por Berg \& Butterfield (1976).

Derivando-se as equações de regressão do logaritmo do peso de músculos, tecido adiposo, ossos da carcaça e peso da carcaça $(\mathrm{kg})$, em função do logaritmo do PCVZ, obtiveram-se as equações de predição dos pesos de músculos, tecido adiposo, ossos da carcaça e peso da carcaça $(\mathrm{kg})$ por kg ganho de PCVZ (Tabela 2).

As equações permitem estimar a participação da carcaça e de seus tecidos (muscular, adiposo e ósseo), na composição do ganho de peso corporal vazio (GPCVZ), das quatro raças zebuínas (Gir, Guzerá, Nelore e Mocho Tabapuã), na faixa de peso

Tabela 2 - Equações de predição do ganho de peso de músculos, tecido adiposo e ossos na carcaça e, ganho de carcaça $(\mathrm{kg})$ por kg ganho de peso de corpo vazio ( $\mathrm{kg} / \mathrm{kg}$ de GPCVZ) para animais zebuínos (Gir, Guzerá, Nelore e Mocho Tabapuã)

Table 2 - Prediction equations of weight gain of muscle, adipose tissue and bone in carcass and, carcass gain $(\mathrm{kg})$ per $\mathrm{kg}$ of empty body weight gain $(\mathrm{kg} / \mathrm{kg}$ of EBWG) from zebu animal (Gyr, Guzerat, Nellore and Mocho-Tabapuã)

Componente Equações de predição

Component Prediction equations

Músculos $\quad \mathrm{Y}^{\prime}=0,576905 * \mathrm{PCVZ}^{-0,103285}$

Muscle

Tecido Adiposo $\quad \mathrm{Y}^{\prime}=0,001842 * \mathrm{PCVZ}^{+0,866648}$

Adipose Tissue

Ossos

Bone

Carcaça

$\mathrm{Y}^{\prime}=0,618612 * \mathrm{PCVZ}^{-0,392111}$

Carcass 
vivo entre 300 e $500 \mathrm{~kg}(246,9$ a 434,3 kg de PCVZ, respectivamente).

Considerando-se animais de 300 e $500 \mathrm{~kg}$ de PV, os resultados do presente estudo mostram ganhos de 0,33 e $0,31 \mathrm{~kg}$ de músculos, 0,22 e $0,36 \mathrm{~kg}$ de tecido adiposo, 0,071 e $0,057 \mathrm{~kg}$ de ossos ou, cerca de 0,66 e $0,70 \mathrm{~kg}$ de carcaça por kg de PCVZ ganho, respectivamente. Aumento mais acentuado do conteúdo de tecido adiposo e decréscimo no crescimento dos músculos e dos ossos foram observados, à medida que o peso dos animais se elevou. Esses resultados encontram suporte em Robelin et al. (1974), Black (1989) e Osório et al. (1994).

As equações de predição dos pesos de carcaça fria e carcaça quente e do peso corporal vazio a partir do peso vivo foram ajustadas para as quatro raças, das categorias de ganho (I, II e III), em conjunto, devido ao pequeno número de animais em cada raça, e em função de as análises anteriores terem revelado comportamento semelhante das quatro raças para praticamente todas as características estudadas.

Verificou-se efeito linear $(\mathrm{P}<0,05)$ de regressão do peso de carcaça quente (PCARQ), peso de carcaça fria (PCARF) e peso corporal vazio (PCVZ), em função do peso vivo (PV) dos animais. As equações são apresentadas na Tabela 3 .

O elevado valor do coeficiente de determinação $\left(r^{2}=0,95\right)$, na equação para predição do PCVZ a partir do $\mathrm{PV}$, mostra bom ajustamento da equação aos dados.

O peso corporal vazio (PCVZ) de um animal com $400 \mathrm{~kg}$ de peso vivo $(341,6 \mathrm{~kg})$, estimado a partir da equação da Tabela 3, foi 2,46\% inferior ao obtido com a equação específica para zebuínos desenvolvida por
Fontes (1995), com base em 101 animais castrados e não castrados e, 1,02 e 0,79\% superior ao obtido por Freitas (1995) e Castillo Estrada (1996), respectivamente. O PCVZ estimado neste trabalho foi praticamente igual ao obtido pela equação de Paulino (1996), que utilizou os mesmos animais do presente estudo, acrescidos daqueles pertencentes às categorias abate inicial (AB) e mantença (AR), e também coincide com àquele encontrado com a equação geral de Fontes (1995).

Consta na Tabela 3 que o peso vivo foi responsável por $88,0 \%$ da variação total dos pesos de carcaça quente e fria, sendo seus coeficientes de regressão positivos, indicando que, a cada quilograma de aumento no peso vivo, os pesos de carcaça quente e fria aumentaram 0,646 e $0,649 \mathrm{~kg}$, respectivamente. Esses resultados estão de acordo com os encontrados por Castillo Estrada (1996), que, utilizando animais Nelore e $F_{1}$ Nelore-Angus, $F_{1}$ NeloreHolandês e $\mathrm{F}_{1}$ Nelore-Normando, verificou que o peso vivo explicou $96,0 \%$ da variação total dos pesos de carcaça quente e fria, com coeficientes de regressão de 0,675 e 0,670 kg, respectivamente. De modo semelhante, guardam concordância com as observações de Zanotta et al. (1980), Osório et al. (1983), Guerreiro et al. (1986) e Jardim et al. (1996).

Os elevados coeficientes de determinação das equações obtidas indicam que as mesmas permitem boa estimativa dos pesos de carcaça quente e fria e do PCVZ. Segundo Fontes (1995), o seu emprego poderá ser de grande utilidade quando os animais experimentais são abatidos em abatedouros comerciais, onde torna-se impossível a determinação do peso corporal vazio.

Tabela 3 - Equações gerais de predição dos pesos $(\mathrm{kg})$ de carcaça quente (PCARQ), de carcaça fria (PCARF) e de corpo vazio (PCVZ), em função do peso vivo (PV), envolvendo animais das quatro raças

Table 3 - Geral prediction equations of hot carcass weight (PCARQ), chilled carcass weight (PCARF) and empty body weight (PCVZ), as a function of live weight (PV) involved animals from four breeds

\begin{tabular}{ccccc}
\hline empty body weight (PCVZ), as a function of live weight (PV) involved animals from four breeds & $\mathrm{r}^{2}$ \\
Equações de predição \\
Prediction equations
\end{tabular}

Significativo $(P<0,01)$.

Significant $(P<.01)$.

R. Bras. Zootec., v.32, n.4, p.986-991, 2003 


\section{Conclusões}

$\mathrm{Na}$ carcaça, o tecido adiposo tem maior impulso para crescimento em idade mais tardia, enquanto o tecido ósseo tem crescimento em idade mais precoce e o tecido muscular, crescimento intermediário.

A carcaça apresenta alometria positiva refletindo o seu desenvolvimento proporcionalmente maior que o do PCVZ.

O peso vivo em jejum pode ser usado para estimar os pesos de carcaças quente e fria e o peso corporal vazio.

\section{Literatura Citada}

AGRICULTURAL RESEARCH COUNCIL - ARC. The nutrient requirements of ruminants livestock. London: Commonwealth Agricultural Bureaux, 1980. 351p.

BERG. R. T.; BUTTERFIELD, R. M. New concepts of cattle growth. New York: Sydney University, 1976. 240p.

BLACK, L.L. Crecimiento y desarrollo de corderos. In: HARESIGN, W. Producción ovina. México: A.G.T. Editor, 1989. p. 23-62.

CASTILLO ESTRADA, L.H. Composição corporal e exigências de proteína, energia e macroelementos minerais (Ca, P, Mg, Na e K), características da carcaça e desempenho do nelore e mestiços em confinamento. Viçosa, MG: Universidade Federal de Viçosa, 1996. 129p. Tese (Doutorado em Zootecnia) - Universidade Federal de Viçosa, 1996.

FONTES, C.A.A. Composição corporal, exigências líquidas de nutrientes para ganho de peso e desempenho produtivo de animais zebuínos e mestiços europeu-zebu. Resultados experimentais. In: SIMPÓSIO INTERNACIONAL SOBRE EXIGÊNCIAS NUTRICIONAIS DE RUMINANTES, 1995, Viçosa, MG. Anais... Viçosa, MG: Universidade Federal de Viçosa, 1995. p.419-455.

FOX, D.G.; DOCKERTY, T.R.; JHONSON, R.R. et al. Relationship of empty body weight to carcass weight in beef cattle. Journal of Animal Science, v.43, n.3, p.566-568, 1976.

FREITAS, J. A. Composição corporal e exigência de energia e proteína de bovinos (zebuínos e mestiços) e bubalinos não castrados, em confinamento. Viçosa: Universidade Federal de Viçosa, 1995. 132p. Dissertação (Mestrado em Zootecnia) - Universidade Federal de Viçosa, 1995.

GRAYBILL, F.A. Theory and aplication of the linear model. Massachussetts: Duxburg Press, 1976. 704p.

GUERREIRO, J.L.V.; OSÓRIO, J.C.S.; FARIAS, J.V.S. et al. Avaliação da produção de carne em novilhos Hereford. I. Estimativas a partir do peso vivo. In: REUNIÃO ANUAL DA SOCIEDADE BRASILEIRA DE ZOOTECNIA, 23., Campo Grande, 1986. Anais... Campo Grande: Sociedade Brasileira de Zootecnia, 1986. p.317.

HANKINS, O.G.; HOWE, P.E. Estimation of the composition of beef carcasses and cuts. Washington, D.C., 1946. (Tech. Bulletin - USDA, 926)
HARVEY, W.R. Mixed model least squares and maximum likelihood computer program (LSMLWM). Versão PC - 1. 1987.

JARDIM, P.O.C.; FARIAS, J.V.; GUERREIRO, J.L.V. et al. Equações para estimar os cortes do traseiro em carcaças de novilhos. In: REUNIÃO ANUAL DA SOCIEDADE BRASILEIRA DE ZOOTECNIA, 19., Piracicaba, 1987. Anais... Piracicaba: Sociedade Brasileira de Zootecnia, 1987. p.226-227.

JARDIM, P.O.C., OSÓRIO, J.C.S., TAROUCO, J.U. et al. Estimativa do peso da carcaça e dos cortes dianteiro, costilhar e serrote a partir do peso vivo em novilhos Hereford. Ciência Rural, v.26, n.2, p.285-288, 1996.

NATIONAL RESEARCH COUNCIL - NRC. Nutrient requeriments of beef cattle. 6.ed. Washington, D.C., 1984. 90p.

NOUR, A.Y.M.; THONNEY, M.L.; STOUFFERR WHITE Jr., W.R.C. Changes in carcass wheight and characteristics with increasing wheight of large and small catle. Journal of Animal Science, v.57, n.5, p.1154-1165, 1983.

OSORIO, J.C.S.; GUERREIRO, J.L.V.; ZONTA, E.P. et al. Determinação do peso de carcaça em novilhos. In: ENCONTRO DE PESQUISA VETERINÁRIA, Pelotas, 1983. Anais... Pelotas: Universidade Federal de Pelotas, 1983. p.2.

OSORIO, J.C.S.; JARDIM, P.O.C.; SIEWERDT, F. et al. Desenvolvimento da composição tecidual da carcaça em bovinos holandês. In: REUNIÃO ANUAL DA SOCIEDADE BRASILEIRA DE ZOOTECNIA, 31., Maringá, 1994. Anais... Maringá: Sociedade Brasileira de Zootecnia, 1994. p.186.

PAULINO, M.F. Composição corporal e exigências de energia, proteína e macroelementos minerais $(\mathrm{Ca}, \mathrm{P}, \mathrm{Mg}, \mathrm{Na}$ e K) de bovinos não-castrados de quatro raças zebuínas em confinamento. Viçosa, MG: Universidade Federal de Viçosa, 1996. 80p. Tese (Doutorado em Zootecnia) - Universidade Federal de Viçosa, 1996.

ROBELIN, J.; GEAY, Y.; BÉRANGER, C. Croissance relative des différentes tissus, organes at régions corporelles des taurillons frisons, durant la phase d'engraissement de 9 a 15 mois. Annales de Zootechnie, v.23, p.313-323, 1974.

TRENKLE, A. The influence of nutrition on growth of beef catle. In: GROWTH MANAGEMENT CONFERENCE, 1983, Indiana. Proceedings... Indiana: IMC, 1983. p.18-25.

WRIGHT, I.A.; RUSSEL, J.F. The composition and energy content of empty body- weigth change in mature cattle Animal Production, v.39, p.365-369, 1984.

ZANOTTA Jr., R.D.L.; JARDIM, P.O.C.; OSÓRIO, J.C.S. et al. Relação entre medidas in vivo e características da carcaça em novilhos de corte. In: SOCIEDADE BRASILEIRA DE ZOOTECNIA, 17., 1980, Fortaleza. Anais... Fortaleza: Sociedade Brasileira de Zootecnia, 1980. p.21. 